\title{
Copper(II) Inhibition of Electron Transfer through Photosystem II Studied by EPR Spectroscopy
}

Caroline Jegerschoeld, Juan B. Arellano, Wolfgang P. Schroeder,

Paul J. M. van Kan, Matilde Baron, and Stenbjoern Styring

Biochemistry, 1995, 34 (39), 12747-12754• DOI: 10.1021/bi00039a034 • Publication Date (Web): 01 May 2002

Downloaded from http://pubs.acs.org on February 27, 2009

\section{More About This Article}

The permalink http://dx.doi.org/10.1021/bi00039a034 provides access to:

- Links to articles and content related to this article

- Copyright permission to reproduce figures and/or text from this article

\section{ACS Publications}




\title{
Copper(II) Inhibition of Electron Transfer through Photosystem II Studied by EPR Spectroscopy ${ }^{\dagger}$
}

\author{
Caroline Jegerschöld, ${ }^{\ddagger}$ Juan B. Arellano, ${ }^{\ddagger}$, Wolfgang P. Schröder, ${ }^{\ddagger}$ Paul J. M. van Kan, ${ }^{\ddagger}$ Matilde Barón, ${ }^{\S}$ and \\ Stenbjörn Styring, ${ }^{*, \not}$ \\ Department of Biochemistry, Arrhenius Laboratories for Natural Sciences, Stockholm University, S-106 91 Stockholm, Sweden, \\ and Department of Biochemistry, Cell, and Molecular Biology of Plants, Estación Experimental del Zaidin, CSIC, \\ Profesor Albareda 1, E-18008 Granada, Spain
}

Received May 1, 1995; Revised Manuscript Received July 19, $1995^{\otimes}$

\begin{abstract}
EPR spectroscopy was applied to investigate the inhibition of electron transport in photosystem II by $\mathrm{Cu}^{2+}$ ions. Our results show that $\mathrm{Cu}^{2+}$ has inhibitory effects on both the donor and the acceptor side of photosystem II. In the presence of $\mathrm{Cu}^{2+}$, neither EPR signal $\mathrm{II}_{\text {very fast }}$ nor signal $\mathrm{II}_{\text {fast }}$, which both reflect oxidation of tyrosine $\mathrm{z}_{\mathrm{z}}$, could be induced by illumination. This shows that $\mathrm{Cu}^{2+}$ inhibits electron transfer from tyrosine $\mathrm{Z}$ to the oxidized primary donor $\mathrm{P} 60^{+}$. Instead of tyrosine $\mathrm{Z}$ oxidation, illumination results in the formation of a new radical with $g=2.0028 \pm 0.0002$ and a spectral width of $9.5 \pm 0.3 \mathrm{G}$. At room temperature, this radical amounts to one spin per PS II reaction center. Incubation of photosystem II membranes with cupric ions also results in release of the $16 \mathrm{kDa}$ extrinsic subunit and conversion of cytochrome $b_{559}$ to the low-potential form. On the acceptor side, $\mathrm{Q}_{\mathrm{A}}$ can still be reduced by illumination or chemical reduction with dithionite. However, incubation with $\mathrm{Cu}^{2+}$ results in loss of the normal EPR signal from $\mathrm{Q}_{\mathrm{A}}^{-}$which is coupled to the non-heme $\mathrm{Fe}^{2+}$ on the acceptor side (the $\mathrm{Q}_{\mathrm{A}}{ }^{-}-\mathrm{Fe}^{2+} \mathrm{EPR}$ signal). Instead, reduction of $Q_{A}$ results in the formation of a free radical spectrum which is $9.5 \mathrm{G}$ wide and centered at $g=2.0044$. This signal is attributed to $\mathrm{Q}_{\mathrm{A}}{ }^{-}$which is magnetically decoupled from the nonheme iron. This suggests that $\mathrm{Cu}^{2+}$ displaces the $\mathrm{Fe}^{2+}$ or severly alters its binding properties. The inhibition of tyrosine $\mathrm{Z}_{\mathrm{Z}}$ is reversible upon removal of the copper ions with EDTA while the modification of $\mathrm{Q}_{\mathrm{A}}$ was found to be irreversible.
\end{abstract}

Copper is an essential micronutrient for higher plants. Despite this, it is also a very potent inhibitor of photosynthetic activity (Droppa \& Horváth, 1990; Barón et al., 1995). Since the first studies on inhibition of photosynthesis by cupric ions (Macdowall, 1949), it has become clear that photosystem II (PS II) ${ }^{1}$ is more sensitive to $\mathrm{Cu}^{2+}$ inhibition than photosystem I (Cedéño-Maldonado \& Swader, 1972). PS II is a large protein complex in the thylakoid membrane with about 20 protein subunits [for reviews, see Andersson \& Styring (1991) and Vermaas et al. (1994a)] that catalyzes the light-driven reduction of plastoquinone by electrons from

\footnotetext{
† This work was supported by the Swedish Natural Science Research Council (S.S.), the Swedish Agriculatural Research Council (W.P.S.) and the Spanish DGICYT (M.B.). J.B.A. acknowledges short-term travelling grants from the Margit and Folke Pehrzon Foundation and the European Science Foundation. C.J. acknowledges support by the Sven and Lilly Lawski's Foundation.

* Correspondence should be addressed to this author at the Department of Biochemistry, Arrhenius Laboratories for Natural Science, Stockholm University, S-106 91 Stockholm, Sweden. Telephone: +468-162420. Fax: +46-8-153679. E-mail: Stenbjorn@Biokemi.Su.Se.

¥ Stockholm University.

$\S$ Estación Experimental del Zaidín.

ه Abstract published in Advance ACS Abstracts, September 1, 1995.

${ }^{1}$ Abbreviations: BBY, PS II membranes prepared by the method of Berthold et al. (1981); Chl, chlorophyll; Cyt, cytochrome; DCIP, 2,6-dichlorophenolindophenol; EDTA, ethylenediaminetetraacetate; EPR, electron paramagnetic resonance; Mes, 4-morpholineethanesulfonic acid; Pheo, pheophytin; PS II, photosystem II; P680, primary electron donor chlorophyll(s) of PS II; $\mathrm{Q}_{\mathrm{A}}, \mathrm{Q}_{\mathrm{B}}$, primary and secondary quinone acceptors; $S$-states $\left(S_{n}\right.$, where $n=0,1,2,3$, or 4$)$, redox states of the oxygen-evolving complex; Tris, tris(hydroxymethyl)aminomethane; Tyr , redox-active tyrosine 161 of the D2 protein; Tyrz, redox-active tyrosine 161 of the D1 protein.
}

water that is oxidized to molecular oxygen (Debus, 1992). A heterodimer of two homologous proteins, the D1 and D2 proteins, constitutes the PS II reaction center that binds all the redox components involved in the photochemistry. This includes the redox-active tyrosine residues $\left(\mathrm{Tyr}_{\mathrm{Z}}\right.$ and $\left.\mathrm{Tyr}_{\mathrm{D}}\right)$, the primary electron donor (P680), the primary pheophytin acceptor, the secondary plastoquinone acceptors $\left(Q_{A}\right.$ and $\left.Q_{B}\right)$, the Mn-cluster involved in the oxidation of water, and the non-heme $\mathrm{Fe}^{2+}$ situated on the acceptor side between $\mathrm{Q}_{\mathrm{A}}$ and $\mathrm{Q}_{\mathrm{B}}$. Also present in the PS II complex is Cyt $b_{559}$ which might alternate between several forms with different oxidation potentials. Cyt $b_{559}$ participates in slow electron transfer reactions in PS II and may function as an electron donor to P680 when the water-oxidizing complex is inactivated (Thompson \& Brudvig, 1988; Buser et al., 1992).

The target for $\mathrm{Cu}^{2+}$ inhibition within the PS II complex is not clear. Several investigations indicate that the site for copper ions is on the donor side of PS II. From spectroscopic measurements, it was suggested that $\mathrm{Cu}^{2+}$ blocked the donor side of PS II close to the water-oxidizing system (Vierke \& Struckmeier, 1977). On the basis of DCIP reduction measurements, it was proposed that the target was between P680 and a donor site localized after the water-splitting system (Shioi et al., 1978; Samson et al., 1988). Similar conclusions have been drawn on the basis of fluorescence measurements (Hsu \& Lee, 1988; Samson \& Popovic, 1988; Renganathan \& Bose, 1989, 1990), where a drastic decrease of maximal fluorescence without changes in the initial $\left(F_{0}\right)$ fluorescence was found in the presence of $\mathrm{Cu}^{2+}$. There are also suggestions that cupric ions interact with the 